\title{
Original article \\ Transition I efficiency and victory in volleyball matches
}

\author{
Herbert Ugrinowitsch \\ Guilherme Menezes Lage \\ Federal University of Minas Gerais, Brazil \\ Suziane P. dos Santos-Naves \\ Federal University of Triângulo Mineiro, Brazil \\ Leandro N. Dutra \\ Maria Flávia S. P. Carvalho \\ Federal University of Minas Gerais, Brazil \\ Alessandra Aguilar Coca Ugrinowitsch \\ The University Center of Belo Horizonte, Brazil \\ Rodolfo N. Benda \\ Federal University of Minas Gerais, Brazil
}

\begin{abstract}
The present study investigated the correlation between Transition I with victory in volleyball matches. The 2002 South-American Youth Men's Championship was recorded and the Transition I was analyzed and classified as negative, null or positive. Results of the efficiency in Transition I was calculated using $t$ test for independent samples and compared to the efficiency between teams during each set and matches. Spearman correlation assessed the relationship between efficiency in each set and results of the matches with the final ranking in the championship. The results showed that the winning teams exhibited higher efficiency in Transition I, as well as a positive relationship of higher efficiency in Transition I with all of their results. The higher efficiency in Transition I is related to victory in volleyball matches.
\end{abstract}

Keywords: sport, volleyball, transitions, skills, efficiency

Resumo - "Eficiência de Transição I e vitória em partidas de vôlei." O presente estudo investigou a correlação entre Transição I com a vitória em jogos de voleibol. O Campeonato Masculino Sul-Americano da Juventude 2002 foi gravado para analisar e classificar Transição I como negativa, nula ou positiva. Os resultados da eficiência na Transição I foram calculados por meio do teste $t$ para amostras independentes para comparação com a eficiência entre as equipes durante cada set das partidas. A correlação de Spearman avaliou a relação entre a eficiência em cada set e os resultados das partidas com a classificação final do campeonato. Os resultados mostraram que as equipes vencedoras exibiram maior eficiência na Transição I, bem como uma relação positiva de maior eficiência na Transição I com todos os seus resultados. A maior eficiência na Transição I está relacionada à vitória em partidas de vôlei.

Palavras-chave: esporte, voleibol, transições, habilidades, eficiência

Resumen-El presente estudio investigó la correlación entre la Transición I con la victoria en las partidos de voleibol. El Campeonato Sur-americanas Hombres Jóvenes 2002 se registró y la transición que se analizó y clasificó como negativo, nulo o positivo. Resultados de la eficiencia en la Transición I se calculó utilizando la prueba $t$ para muestras independientes y se compara con el rendimiento entre los equipos en cada set y partidas. Correlación de Spearman evaluó la relación entre la eficiencia en cada conjunto y los resultados de las partidas con la clasificación final del campeonato. Los resultados mostraron que los equipos ganadores exhibieron una mayor eficiencia en la Transición I, así como una relación positiva de una mayor eficiencia en la Transición I con la totalidad de sus resultados. La mayor eficiencia en la Transición I se relaciona con la victoria en las partidas de voleibol.

Palabras clave: deporte, voleibol, transiciones, habilidades, la eficiencia 


\section{Introduction}

Volleyball is considered one of the most difficult sports because one can neither grab nor touch the ball twice consecutively. Moreover, the cyclic characteristic of volleyball skills adds some obscurity about the analysis of this sport, and, consequently, it is difficult to know about the most important skill that leads to a match victory. Some studies investigated anthropometric parameters and vertical jump performance of athletes (Fattahi, Ameli, Sadeghi, \& Mahmoodi, 2012). However, victory in volleyball matches means scoring more points than the opponent (Miskin et al., 2010); therefore, other studies tried to identify the most important skill that was associated to a match victory. Although some studies (Hughes and Daniel, 2003) found that service and reception are the volleyball skills that differentiate elite from non-elite players. Cox (1974) found that spiking is the best predictor of a teams' success, followed by digs. Ejem and Horak (1980) found different results, where spikes followed by reception were the decisive winning factors. However, for Nishijima, Ohsawa and Matsura (1987), the best predictors are spikes followed by hits performed by the setter. Based on these results it is impossible to define what is the decisive winning factor or the most efficient scoring tactics in volleyball. Even though most of the studies showed the importance of spikes as a decisive factor, followed by skills like reception and setting, Marcelino et al. (2010) fail to find any difference when analyzed the spikes performed by the top eight teams of the FIVB Men's World Cup 2007.

It is necessary to point out that the studies above mentioned did not distinguish the spikes executed during the attack from the spikes executed during the counter-attack. This distinction inspired Hebert (1991), and Eom and Schutz (1992a) to analyze volleyball in a different way and describe it as two specific processes: attack, or Transition I, and counter-attack, or Transition II. It may be a pitfall because there is a cyclic process after the first transition, which had not been addressed before. Assuming that there is neither a serve "ace" nor a server error, or a setter spike, the game will be won by players attacking (spikes) and/or blocking.

As Figure 1 shows, two different spikes occur in Transitions $I$ and $I I$, so they should be analyzed differently. The main goal of Transition II is to score points through a block or a counter-attack, and get advantage over the opponent, especially when the team that complete the counter-attack had serviced. This process makes it possible to "win a match" because one team can score more points than its opponent, an idea corroborated by Eom and Schutz (1992b). Otherwise, the main function of Transition I for the team that receives the service is to place the ball in the opponent's court, to touch any opponent, and then go off the game area-or to induce an infraction by the opponent such as touching the net. Whether one of these things happens, the opponent cannot score points. Following this reasoning, it is clear, as a process, that the team that score $100 \%$ of the points in Transition I never lose the game, or even more realistically, the team that score more points in Transition I cannot lose the game.
Transition I

Transition II

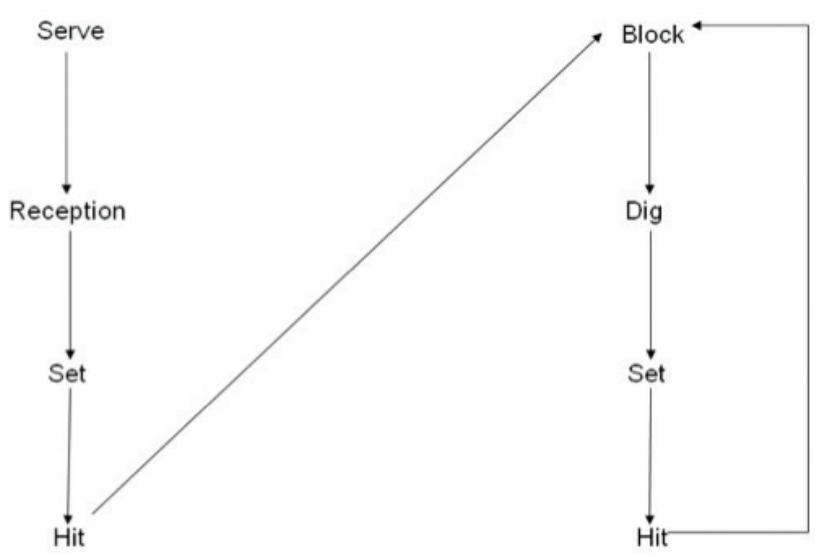

Figure 1. Transition I (attack) and Transition II (counter-attack) processes in volleyball game.

Hence, Transition I might be understood as the process when a team "does not lose" the game, and Transition II as the process when a team "wins" the game. This idea can help to understand volleyball as a process.

Although Transition II allows scoring advantage over the opponent without a good performance in Transition I, it is still possible to lose the game. For example, a team that scores one point for every three points scored in Transition II might lose the game, while the other team scores just one point for every two points scored in Transition I. Based on this reasoning, the first way of winning a volleyball game is by not giving the opponent the opportunity to score. Therefore, a good performance in Transition I is crucial to prevent the opponent from scoring using blocking and/or counter attacking in Transition II. Then, the question whether Transition $I$ is a decisive factor for the victory in volleyball naturally arises.

To highlight the issue, Schwalm, Ugrinowitsch and Ugrinowitsch (1995) investigated this question with the top four under-19 Boys' Championship teams of São Paulo State, Brazil. Although the results gave support for the Transition $I$ efficiency and victory, their conclusion had limited value as it was based on a side out score system rather than on a rally score system. However, the analysis of the volleyball skills in Transition I in the Brazilian Men's National Championship did not show difference for attack actions (Rocha \& Barbanti, 2004). They found that in Transition I, the confrontation spike versus the block actions seem to be the most important factor to predict the volleyball outcome (Rocha \& Barbanti, 2006). However, the first study did not separate the attack from both transitions. There is a gap in the literature with regard the comparison of performances of opponents in Transition I. We hypothesized that a better efficiency in Transition $I$ helps not to lose sets/matches, as well as Transition I is related to a better final championship ranking in volleyball rally score system. 


\section{Method}

\section{Sample}

The eight 2002 South-American Youth Men's Championship teams participated as sample. This championship adopted the rally score system, and each team played against all the others, which meant that the team that obtained the highest number of victories won the championship. This is an important characteristic to test the paradigm since all teams played against each other, and the final result was not a play-off, but the result of the performance throughout the competition. This research complies with the Local Ethic Committee (n. 0055.0.203.000-05).

\section{Procedures and design}

In order to analyze Transition I, only the "final result" of the attack process was considered. All games were recorded for future analysis. Typically, frequency (percentage) is the dependent variable used in this type of study (Cox, 1074; Nishijima; Marcelino et al., 2010; Ohsawa \& Matsura, 1987), but we adopted Transition I efficiency (Ef) as explained below. To achieve this goal, an ordinal three-level scale was applied: 1. (-) negative spike (the ball hit the net, was blocked or off court, resulting in points for the opponent),

2. (0) null spike (the ball remained in play), and

3. (+) positive spike (the ball went into the opponent's court or off the game area after touching an opponent with a resulting score).

$$
\mathrm{Ef}=[(+ \text { spikes })-(\text {-spikes })] / \text { total spikes }
$$$$
\text { (Hebert, 1991; Beal et al., 1992) }
$$

Null spikes ( 0 ) are not considered the numerator in the calculation of spike efficiency. They are not very important for spike efficiency because null spikes do not affect the outcome of the disputed point as the ball remains in play. However, this measure is different from frequency, which uses only positive spikes in the numerator. Particularly, this difference is decisive to test the hypothesis that Transition I helps to do not lose sets and games.

An index card was used for data collection for each match set. Each card contained the number of each player, and their respective rotation order of both teams. Hence, the collected data provided information regarding the efficiency of each player, rotation, set, and match. In this article, we analyzed the efficiency of Transition I in each set and match. Finally, championship efficiency was found by the summation of all matches efficiency.

\section{Data analysis}

The efficiency of all teams in Transition I was calculated and specified as "sets" and "matches" in all games played during the championship for data analysis. The hypothesis that a better efficiency in Transition I helps to not lose sets/matches was tested through the $t$ test for independent groups comparing the efficiency in Transition I separately for sets and matches, comparing winning and losing teams. Subsequently, the hypo- thesis that the highest efficiency in Transition I would have a better outcome in the championship ranking of the volleyball rally score system was tested using Spearman correlation test to assess relationship between efficiency in set and match results with the final championship ranking. The statistical package Statistic for Windows 7.0 was used with significance level of .05 .

\section{Results}

In order of test the hypothesis that a higher efficiency in Transition I would help not lose a set and a match in volleyball, efficiency was measured separately in both. Based on the efficiency formula herein presented, the highest efficiency is equal to 1 when a team scores all spikes; the lowest efficiency is equal to -1 when a team misses all spikes, which means $100 \%$ and $-100 \%$, respectively. Figure 2a illustrates that the winning teams exhibited higher efficiency in sets than the losing teams, except for two of them. The $t$ test showed that this difference was statistically significant $[t=7.27, p<.01]$. Moreover, Figure $2 \mathrm{~b}$ shows that the winning teams exhibited higher efficiency in matches than the losing teams. The $t$ test showed that this difference was statistically significant $[t=5.74, p<.04]$.
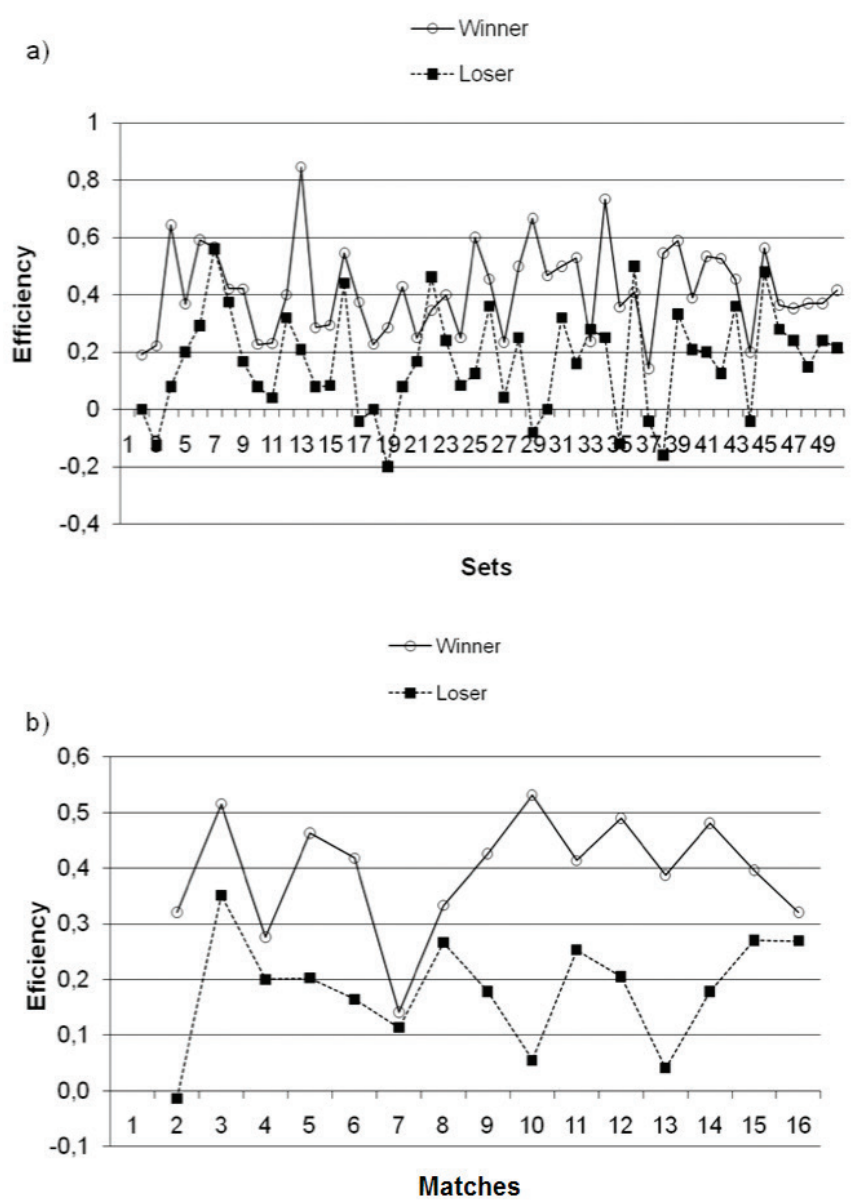

Figure 2. Efficiency in Transition I of the winner and loser teams in each set (a); efficiency in Transition I of the winner and loser teams in each game (b). 
In order of test the hypothesis that the highest efficiency in Transition I would result in a better championship ranking outcome in volleyball, another analysis via correlation test was performed for identifying relationships between the higher efficiency in Transition I and the victory in sets and matches. The first correlation compared efficiency in the sets played by the winning and losing teams with the results of the sets. A significantly low negative correlation between the efficiency in Transition I of winning teams and the losing sets was found $[n=49, r=-31.29, p<.01]$. These results indicate that the losing teams did not show high efficiency in Transition $I$. The test also showed positive correlation between efficiency in Transition I of the losing teams with the losing sets $[n=49, r=44.55, p<.01]$, indicating that the teams with low efficiency in Transition I lose the sets. The same test was conducted to analyze efficiency of Transition I with the winning and the losing matches. The results showed negative correlation between the efficiency of Transition I of winning teams with the losing matches $[n=15$, $r=-66.71, p<.05]$, indicating that the teams with low efficiency in Transition I lost the matches. Finally, correlation between total efficiency in Transition $I$ and final championship ranking showed high significance $[n=6, r=94.3, p<.04]$, indicating that the teams with high efficiency in Transition I reached the highest positions in the championship rank.

\section{Discussion}

We proposed to study the efficiency of Transition I to analyze victory in volleyball games, rather than analysis of individual skill frequency (e.g., Nishijima; Ohsawa \& Matsura, 1987; Rocha \& Barbanti, 2006). The analysis of isolated skills might lead to the moot point when one specific skill is responsible for the victory in a volleyball match. In general, the results of the present study support this notion because most of the teams that won the sets and the matches reached higher efficiency. Matias and Greco (2011) found relationship between set and hit, which gives support to the proposal of analyzing the volleyball game as Transitions, but they analyzed all spikes together. We proposed that Transition I helps a team not lose sets and matches; contrary to Transition II that helps the team to win sets and matches.

Based on this proposal we tested the hypothesis that a higher efficiency in Transition I would help a team not to lose sets and matches in volleyball. Our results support this claim, since the teams that had higher efficiency in Transition I won nearly all sets and won all the matches. In fact, the team with higher efficiency in Transition I lost only two of 50 sets, corroborating the early proposal of Eom and Schutz (1992a) and the results of Schwalm, Ugrinowitsch and Ugrinowitsch (1995). These studies showed the importance of distinguishing spikes performed in Transition I from Transition II, as suggested before, and contrasted with the results by Rocha and Barbanti (2004) that analyzed all spikes lumped together. Consequently, our results showed that Transition I may be a good predictor of a match result, corroborating the findings of McGarry, Anderson, Wallace, Hughes and Franks (2002) that claim that it is necessary to analyze the volleyball game as a transition instead of isolated skills.
Our second hypothesis that Transition I efficiency is related to a better outcome in the championship ranking using the volleyball rally score system is also supported by our results. First of all, the analysis of the efficiency in Transition I and the results of the sets showed negative correlation between high efficiency and losing sets, indicating that the team with higher efficiency in Transition I did not lose the game. Moreover, the positive correlation between the lower efficiency of the losing teams and the results of losing sets indicates that one team with low efficiency in Transition I probably loses the set. Second, the analysis of the efficiency in Transition I and the results of the matches shows negative correlation between the efficiency of the winning teams and the results of the losing matches indicating that the teams with higher efficiency probably win volleyball matches. In general the results shows that the higher the efficiency in Transition I the lower the probability of losing a set/match, which means that, empirically, we have improved the idea of Eom and Schutz (1992b).

The characteristic of the championship (one team plays against all) makes more important to have one good measure to discriminate the team with potential to win matches, because this team will likely wins the championship. We found a positive correlation between higher efficiency in Transition I (i.e., the total efficiency during the whole championship) with the final ranking indicating the importance of effectively performing all spikes to win the ball possession as proposed by Hebert (1991), but specifically during Transition I. This result supports the idea that Transition I occurs when the team does not lose the match. However, it is still necessary to find one measure to analyze the relationship between the skills in Transition I because in this study we analyzed the results from this transition and not its process.

In general, our results provide at least two work planning guidelines for volleyball coaches: a) since the results show the correlation between Transition I efficiency and volleyball victories, coaches may base the season practice planning to obtain an efficiency higher than that of the opponents (Hebert, 1991); and b) it is not worth practicing isolated skills since winning is not accomplished by the simple sum of reception, setting, and spiking skills, but by the way they interact and that new structures that emerge during the game, that is, the organization of Transition I.

\section{Conclusion}

In conclusion, our results showed that high efficiency in Transition I contributes to win sets and matches, as well as to better rank in the championship, showing that the team who is successful in Transition I does not lose the game. These results can provide information for coaches to plan their practice based on the efficiency in Transition I by the best team in a championship.

\section{References}

Beal, D., et all. (1992). Volleyball Notes. Conducted by The Sports Group, Inc. 
Cox, R.H. (1974). Relationship between volleyball skill components and team performance of men's Northwest "AA" volleyball teams. Research Quarterly, 45, 441-446.

Ejem, M., \& Horak, J. (1980). Selected findings from statistical analysis of individual in Czechoslovakia championships. Volleyball Tech Journal, 5, 17-30.

Eom, H.J., \& Schutz, R.W. (1992). Statistical Analysis of Volleyball Team Performance. Research Quarterly for Exercise and Sport, 63, 11-18.

Eom, H.J., \& Schutz, R.W. (1992). Transition Play in Team Performance of Volleyball. Research Quarterly for Exercise and Sport, 63, 261-269.

Fattahi, A., Ameli, M., Sadeghi, H., \& Mahmoodi, B. (2012). Relationship between anthropometric parameters with vertical jump in male elite volleyball players due to game's position. Journal of Human Sport and Exercise, 7, 714-726.

Hebert, M. (1991). Insights and Strategies for Winning Volleyball. Illions: Human Kinetics.

Hughes, M., \& Daniel, R. (2003). Playing patterns of elite and non-elite volleyball. International Journal of Performance Analysis in Sport, 3, 50- 56.

Marcelino, R., Mesquita, I., \& Sampaio, J. (2010). Efficacy of the volleyball game actions related to the quality of opposition. The Open Sports Science Journal, 3, 34-35.

Matias, C.J.A.S., \& Greco, P.J. (2011). Análise da organização ofensiva dos levantadores campeões da superliga de voleibol. [Offensive organization assessment of winners of brazilian volleyball superleague setters]. Revista Brasileira de Ciências do Esporte, 33, 1007-1028.

Mcgarry, T., Anderson, D.I., Wallace, S.A., Hughes, M.D., \& Franks, I.M. (2002). Sport competition as a dynamical self-organizing system. Journal of Sports Science, 20, 771-781.

Miskin, M.A., Fellingham, G.W., \& Florence, L.W. (2010). Skill Importance in Women's Volleyball. Journal of Quantitative Analysis in Sports, 6, 1-12.

Nishijima, T., Ohsawa, S., \& Matsura, Y. (1987). The relationship between the game performance and group skill in volleyball. International Journal of Physical Education, 24, 20-26.

Rocha, C.M., \& Barbanti, V.J. (2004). Uma análise dos fatores que influenciam o ataque no voleibol masculino de alto nível. [One analysis of factors that influence the attack in high level male volleyball]. Revista Brasileira de Educação Física e Esporte, São Paulo, 18(4), 303-314, 2004.

Rocha, C.M., \& Barbanti, V.J. (2006). Brazilian volleyball: an analysis of the confrontations in the first sequence of game action. Journal of Human Movement Studies, 50, 258-272.

Schwalm, G., Ugrinowitsch, H., \& Ugrinowitsch, C. (1995, April). Eficiência no Side-Out e Vitórias nos Jogos de Voleibol. [The side out efficiency and the winning in volleyball]. In: Anais do $I$ Momentum Congresso Brasileiro sobre Qualidade na Educação Física e no Esporte, Curitiba.

\section{Authors' note}

Herbert Ugrinowitsch (herbertu@ufmg.br), Guilherme Menezes Lage (menezeslage@gmail.com), Leandro N. Dutra (dutraln@gmail. com), Maria Flávia S. P. Carvalho (totscarvalho@yahoo.com.br) and Rodolfo N. Benda (rodolfobenda@yahoo.com.br) are with the Federal University of Minas Gerais.

Address: Av. Antonio Carlos, 6627, Pampulha, Belo Horizonte, MG, 31270-901, Brazil
Suziane P. dos Santos-Naves (suzi.ps@ig.com.br) is with the Federal University of Triângulo Mineiro

Address: Rua Frei Paulino, 30 - Abadia, Uberaba, MG, 38025-180, Brazil

Alessandra Aguilar Coca Ugrinowitsch (coca.ugri@yahoo.com.br) is with the Central University of Belo Horizonte

Address: Av. Prof. Mário Werneck, 1685, Estoril, Belo Horizonte, MG, 30455-610, Brazil

Manuscript received on March 28, 2013

Manuscript accepted on January 27, 2013

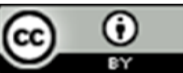

